\title{
Research on the Construction of Equipment Maintenance Support System
}

\author{
Xu Xiangjun ${ }^{1,}$ Liu Zhongmin ${ }^{1,}$, Zhou Zelong $^{1,}$, Xie Rongyue $^{1,}$ \\ Wuhan Mechanical College, Wuhan, 430075, China \\ ${ }^{\mathrm{a}}$ email
}

Key words: Equipment Maintenance, Security System, Countermeasure

\begin{abstract}
Focus on deepening the reform of national defense and the armed forces of the new requirements, the army's weapons and equipment rapid renovation and development of the new situation and analysis of equipment maintenance support system existing problem and should have the ability, distinguished from the maintenance tasks, personnel allocation structure, maintenance mode innovation, protection of resources distribution, the power of civil military integration, puts forward the countermeasures and measures of construction and reform of the equipment maintenance support system.
\end{abstract}

\section{Analysis of Existing Problems in Equipment Maintenance Support System}

With preparations for military struggle unceasingly thorough, the equipment maintenance support system is becoming more and more perfect, a strong guarantee for the army combat readiness training and carry out diversified military tasks. But in the face of the new requirements of deepening the reform of national defense and the armed forces, facing to the new situation of rapid renovation and development of the army's weapons and equipment, equipment maintenance support system construction still exist many deep-seated problems need to be further studied and solved.

Firstly, the military's various levels of maintenance support task is not reasonable. For a long time, the implementation of our army is to overhaul, repair, minor repairs three repair grade and base level, intermediate level, level three level maintenance system for the main body of the equipment maintenance support system structure. Set up the maintenance level, task allocation and operation mode is based on mechanization and semi mechanization stage equipment support of the characteristics and laws of the understanding, the presence of scattered resources, task overlapping problem, already can not adapt to the technical characteristics and requirements of the high technology equipment maintenance.

Secondly, the "Army General equipment system security, filled with" mutual protection mechanism has not been established. Armies of general equipment, has not established a corresponding guarantee mechanism and maintenance division of tasks, although in the implementation of earthquake disaster relief in diversified military tasks, around the "links traditional insurance, packed with each pass" to explore some useful practical results, but because of the many factors involved, usually basically or self security. Among the various professional categories, the security elements are segmentation, repeated construction and waste of resources, no security forces have occurred from time to time. Such as self-propelled gun maintenance and tanks and other armored vehicles repair professional is very similar, but belong to armament and armor two business unit management, each array, self-contained, redundant construction, security resources can not be shared, other branches of the military also similar.

Thirdly, the equipment maintenance support forces into and can't meet the requirement of task. At present, our military equipment maintenance and support force organized by the Central Military Commission, the military services, the theater repair plant,) and corps level units below the 
maintenance unit. From the perspective of troops, battle of maintenance and support force of preparation of small, fewer personnel, professional settings can't cover the existing military weapons and equipment wartime inadequate direction in the configuration of power by, base maintenance and maneuver support task contradiction. Brigade, regiment level maintenance and support force is generally weak, less the number of preparation, professional elements, junior and senior high school office equipment professional and technical cadres and professional technical sergeant personnel proportion is unreasonable, especially armor, artillery, air defense, engineer brigade (Regiment) etc. equipment high technology content of branches of the armed forces, senior engineers, engineers and senior NCOs slants little, is not conducive to the cultivation of reserve technical backbone. New outfit after failed to adjust the supplement of maintenance personnel, supplementary information system equipment integrated information construction equipment there is no corresponding maintenance technical positions.

Fourth, the integration of military and civilian equipment maintenance is still in the initial exploration stage. Due to the present civil military integration equipment maintenance support system is not really set up, military and civilian maintenance interface is not clear, division of tasks is not clear, some troops hi-tech equipment problems, rely on manufacturers and research institutes, and even crossed the superior equipment maintenance management departments directly to find manufacturers, extent formed order of society guarantee maintenance is not standardized, the effect of unstable situation.

\section{The Basic Goal of Equipment Maintenance Support System Construction}

In order to meet the requirements of equipment maintenance support in the new situation, the maintenance support system should be established with the aim of forming the actual combat support ability and the requirement of "broad spectrum", "wide area" and "wide time". "Broad-spectrum" is the maintenance of the security system to be able to meet all war equipment maintenance support needs; "wide area" is the maintenance of the security action to be able to meet in combat to amplitude and expansion of maintenance need; "popular" is the maintenance of the security behavior to be able to adapt to the peacetime and wartime Peace War conversion of need. Embodied in the following four aspects.

Firstly, the quick response ability. Based on the combat mission, rapid completion of various security elements of the transformation from peacetime to wartime, established wartime compiled and protection of resources in wartime system, form a wartime security maintenance unit maintenance and social security agencies at all levels. Therefore, the maintenance and support system must have compatible peacetime strength of the establishment, operation mechanism of peacetime engagement, peacetime and wartime general support resources.

Secondly, the high mobility charged with security maintenance and guarantee institution in the area of operations, with accompanying battle group implementation in situ salvage and repair ability; mobile support the maintenance and guarantee institution bears in the area of operations, with remote delivery of support capability. Therefore, maintenance agencies at all levels should have a high degree of mechanization, maintenance resources to adapt to mobility, articles for configuration form.

Thirdly, the ability of real time is controlled. Maintenance support system usually have management ability to control the whole system in the maintenance of quality maintenance benefits as the center, with the wartime command coordination elements to guarantee for the rapid and accurate target. Therefore, the informatization level of maintenance support system should be higher. With the operating environment, with wartime network, database management, command, 
control and communication platform based on information system.

Fourth, a comprehensive support capability. Responsible for maintenance support system with various types of equipment in peacetime and wartime rescue capability level repair. Therefore, the system security functions to closely link, means to guarantee the configuration to be highly integrated, security methods to apply efficiency, ensuring the supply of resources to timely and accurate.

\section{Countermeasures and Measures for the Construction of Equipment Maintenance Support System}

Equipment maintenance support system construction, we must adhere to the goal of strengthening the military to centralize, subject to the overall situation of national defense and military reform, in accordance with the "adjustment functions, straightening out relations, give prominence to the key points, optimize the structure, improve efficiency, explore to solve maintenance task division, the personnel allocation structure, maintenance mode innovation, security resource allocation, military and civilian power integration, and constantly improve the information system of system combat capability of equipment support based on.

Adjust the division of equipment maintenance and support tasks. Adapt to the usual regional integration and maintenance of wartime rapid rescue repair requirements. According to the integration of high-tech equipment support ability, down to strengthen the idea of comprehensive support capability of the troops, the science division of the forces at all levels of the repair mechanism of maintenance tasks to explore by base level, intermediate level, level three level maintenance system of the main changes to the base level, unit level maintenance system approach road. Base level, mainly responsible for equipment overhaul, high-tech equipment repair, component repair, commissioning and support mission support; force level, mainly responsible for self-contained for pieces repair, repair and maintenance and repair and detection, network debugging, component replacement, upgrade software tasks.

Accomplish a good job of equipment maintenance and use of power allocation. One is to optimize the personnel structure, and increase the photoelectric reconnaissance, radar, command and communication, software and other high-tech professional maintenance and support force, in above the regiment troops addendum a based on information charges equipment maintenance repair classes; adjust brigade or regiment repair agency personnel allocation structure, improve the proportion of senior technical staff and technical sergeant. Second is to strengthen the professional integration, adjust to repair unit according to the reality of the army, the same professional, functionally similar types of professional integration; to add new equipment and troops are in urgent need of maintenance security professional preparation, reduction of old equipment maintenance support professional preparation; in battalion set up equipment maintenance support staff positions, prominent maintenance and simple fault elimination training, improve self-protection ability. Three is to implement the scientific grouping, according to the small scale, full function, good mobility, survivability requirements, system support force integration, rescue equipment repair and maintenance equipment supply and command and communications, defense force according to the operational needs of mixed grouping, the preparation of command, maintenance, support and battlefield defense function, can alone carry out maintenance tasks.

Reform the way and method of equipment maintenance support. One is aimed to improve the peacetime repair benefit and the wartime salvage and repair ability, implementing intensive repair, including self-contained for repair parts and components concentration item repair, repair parts size, high technology system patrols repairs. : to replace the assembly (components, modules), in the 
theater repair organization, focus on specialized repair; the need for processing or repair parts, in the theater repair organization, unified organization of the batch production, repair of scale; of technology is complex and is not easy to changing parts repair, and difficult to organize a repair of high technology equipment system, the superior to take technical support, circuit repair. Two is around the maintenance mode, maintenance content, maintenance interval and other key elements, adjust the level of equipment maintenance. Namely: mechanized equipment to use large, medium and minor repairs and maintenance level of maintenance; equipment information according to the maintenance and testing fault diagnosis, replacement of components, upgrade software, component repair, commissioning and set up a maintenance level; missile ammunition maintenance, testing and replacement of components according to the establishment of maintenance level. Three is to explore the establishment of repair industry and trade in the main system, is in charge of the camp even the front-line officers and operation, daily maintenance skills training, responsible for the subordinate companies learning equipment inspection, maintenance and repair, equipment of level cannot be repaired, the superiors for maintenance.

Integrated equipment maintenance support resources. Follow the "adjusted according to the task of streamlining, according to needs with the construction principle, to distinguish on the basis of the new maintenance tasks, focusing on the maintenance support resources general, combination, and a series of integration, forming and adapt to all levels of maintenance task of maintenance resource allocation system. Battle repair mechanism, increasing the number of components from the repair, repair parts size, high technology system inspection repair high-tech means of condition monitoring, detection, efficient repair and information management, improve the repair quality and efficiency, integration and optimization of maintenance equipment and equipment turnover container means, improve the standardization, seriation, the level of integration, optimization of support equipment series, improve the mobility support ability, forming adapted to equipment development, peacetime and wartime compatible resource allocation system, guarantee ability and support ability to the advantage of the allocation of resources to improve the battle repair and radiation mechanism of the subordinate units. Group team belongs to a repair mechanism, key configuration equipped for repair and rapid wartime salvage and repair the desired combination, intelligent, field maintenance tool, used to reduce the component repair, renovation of the old product, parts processing system with fixed maintenance tool and equipment, forming adaptation usually change parts repair and wartime with required resources distribution system security, simplification of the allocation of resources to improve group belongs to a repair facility with protection ability.

Improve civil military integration equipment maintenance support operation mode. One is the in-situ joint protection and for the maintenance and support force forces could not solve, after the expiration of the warranty period and a column mounted a large amount of equipment failure, repair the coordinating body at the base level, and equipment repair factory or research commitment manufacturing units composed of support group, go to the troops stationed on the equipment fault repair. The second is packaged component repair, the troops do not have repair ability to be repair parts, special repair equipment sent to designated equipment repair factories or research commitment manufacturing units to carry out repairs. Third is the special system contract, for smaller quantities, technical content higher equipment independent system, military and contractor signed a technical support and major tasks of the special protection of the agreement, the equipment repair factory or research commitment manufacturing units in accordance with the agreement of organization implementation of maintenance and support activities, army repair organization no longer bear the maintenance task. Fourth, technical support services, at the beginning of the troops in the delivery of new equipment, equipment bearing research manufacturing units of army 
personnel are professional and technical training, implementation of remote fault diagnosis, maintenance, guidance, metrological verification, data query and special materials, equipment, oil special supply maintenance guarantee, to ensure the rapid formation of equipment of combat and security forces. Fifth, networking equipment for, link building covers all equipment research commitment manufacturing units and headquarters and theater equipment warehouse, and various repair mechanism of joint equipment reserve supply network, according to the principle of the nearest and handy, calling in a timely manner required for equipment, improve equipment please collar, shipping, receiving, storage and release process of speed and accuracy.

\section{Conclusion}

This paper presents the key points of analysis of existing problems in equipment maintenance support system. The basic goal of equipment maintenance support system construction is put forward, and the countermeasures and measures for the construction of equipment maintenance support system are pointed out.

\section{References}

[1] Wang Yunbi. The research of the organization and command of the diversified military mission [M]. Beijing: Military Science Press, 2011.

[2] Yu Hongmin, General equipment support [M]. Beijing: National Defence Industry Press, 2013.

[3] Ruan Yongjun, Joint operational equipment support research [M]. Shijiazhuang: Ordnance Engineering College, 2006. 